\title{
Uji Aktivitas Ekstrak Biji Caesalpinia Sp terhadap Jumlah Eritrosit Mus musculus yang Diinfeksi Plasmodium berghei serta Implementasinya dalam Pembelajaran Kimia
}

\author{
Nurleli $^{1,2 *}$, Agus Sundaryono ${ }^{2}$ dan Aceng Ruyani ${ }^{2}$ \\ ${ }^{1}$ MAN 1 Kota Bengkulu \\ ${ }^{2}$ Pascasarjana Pendidikan IPA, FKIP Universitas Bengkulu \\ *Email: nurleli.pendipa@gmail.com
}

\begin{abstract}
[Activity test of Caesalpinia sp seed extract on erythrocytes amount of Mus musculus infected by Plasmodium berghei and its implementation in chemistry learning]. The aims of this study were to (1) determine the activity of seed extract (Caesalpinia sp) on the number of Erythrocytes of M. Musculus of Swiss Webster Strain infected by P.berghei, (2) Find the active compounds obtained from the isolation of Caesalpinia sp seed extract (3) Find the differences in student learning outcomes about the separation of secondary metabolites using thin layer chromatography (TLC) which is taught in chemistry learning by using LKS. In this study Caesalpinia sp seed extract was purified by thin layer chromatography and column coromatography, and was identified by IR and 1H-NMR spectroscopy. M. musculus infected with P. berghei was given Caesalpinia sp seed extract at a dose of $0.028 \mathrm{~g} / \mathrm{Kgbb}, 0.056 \mathrm{~g} / \mathrm{Kgbb}$, and $0.084 \mathrm{~g}$ / Kgbb by gavage, while the positive control group was given Kloroquin diphosphate, negative control was given olive oil. Caesalpinia sp seed extract with a dose of $0.056 \mathrm{~g} / \mathrm{Kgbb}$ inhibited the highest plasmodium, which was $42.89 \%$ and even exceeded the malaria drug commonly used chloroquin diphosphate $29.85 \%$. Caesalpinia sp seed extract capable of reducing plasmodium in erythrocytes is also able to increase the number of uninfected erythrocytes. The active compounds obtained from the isolation of Caesalpinia $s p$ seed extract are alkaloids, flavonoids, saponins, and terpenoids. In the implementation of extracurricular group learning is taught by using worksheets. There are significant differences where the average posttest score is 88.67 and the average pretest is 32.1 .
\end{abstract}

Keywords: Caesalpinia Sp.; Erythrocyte; Plasmodium berghei; Mus muscullus; Student working sheet.

\begin{abstract}
ABSTRAK
Penelitian ini bertujuan untuk (1) mengetahui aktivitas ekstrak biji kebiul (Caesalpinia sp) terhadap jumlah eritrosit mencit M.musculus jantan Swiss Webster yang telah diinfeksi P.berghei, (2) mengetahui senyawa aktif yang didapat dari isolasi ekstrak biji Caesalpinia sp, (3) mengetahui perbedaan hasil belajar siswa tentang pemisahan senyawa metabolit sekunder dengan menggunakan kromatografi lapis tipis (KLT) yang diajarkan pada pembelajaran kimia dengan menggunakan LKS. Pada penelitian ini ekstrak biji Caesalpinia $s p$ dimurnikan dengan kromatografi lapis tipis dan koromatografi kolom, serta diidentifikasi dengan spekstroskopi IR dan ${ }^{1} \mathrm{H}-\mathrm{NMR}$. M.musculus jantan Swiss Webster yang terinfeksi P.berghei diberi ekstrak biji Caesalpinia sp dengan dosis $0.028 \mathrm{~g} / \mathrm{Kgbb}, 0.056 \mathrm{~g} / \mathrm{Kgbb}$, dan $0.084 \mathrm{~g} / \mathrm{Kgbb}$ secara gavage, sementara kelompok kontrol positif diberikan Kloroquin diposfat, kontrol negatif diberi minyak zaitun. Ekstrak biji Caesalpinia sp dosis $0.056 \mathrm{~g} / \mathrm{Kgbb}$ menghambat plasmodium paling besar yaitu $42.89 \%$ bahkan melampaui obat malaria yang umum dipakai kloroquin diposfat $29.85 \%$. Ekstrak biji Caesalpinia sp mampu menurunkan plasmodium dalam eritrosit juga mampu meningkatkan jumlah eritrosit yang tidak terinfeksi. Senyawa aktif yang didapat dari isolasi ekstrak biji Caesalpinia sp adalah alkaloid, flavonoid, saponin, dan terpenoid. Pada implementasi dalam pembelajaran kelompok ekstrakurikuler diajarkan dengan menggunakan LKS. Terdapat perbedaan yang nyata dimana rata-rata nilai postes 88.6667 dan rata-rata pretes 32.1333 .
\end{abstract}

Kata kunci: Caesalpinia Sp.; Eritrosit, Plasmodium berghei; Mus muscullus; LKS. 


\section{PENDAHULUAN}

Penggunaan bahan alam sebagai obat tradisional di Indonesia telah dilakukan oleh nenek moyang kita sejak berabad-abad yang lalu. Indonesia dengan jumlah penduduk lebih dari 200 juta jiwa, memiliki lebih kurang 30.000 spesies tumbuhan dan 940 spesies di antaranya termasuk tumbuhan berkhasiat obat. Tumbuhan tersebut menghasilkan metabolit sekunder dengan struktur molekul dan aktivitas biologi yang beraneka ragam serta memiliki potensi yang sangat baik untuk dikembangkan menjadi obat berbagai macam penyakit (Marwoko, 2013). Senyawa kimia aktif yang berasal dari tumbuhan sangat penting dalam bidang pengobatan, metabolit sekunder dalam tumbuhan biasanya tersebar merata keseluruh bagian tumbuhan tetapi dalam kadar yang berbeda. Sangat banyak jenis tumbuh-tumbuhan yang digunakan untuk obat-obatan yang dikenal sebagai obat tradisional sehingga diperlukan penelitian tentang tumbuhan berkhasiat dan senyawa kimia yang berfungsi sebagai obat. Tumbuhan yang mengandung senyawa metabolit primer dan metabolit sekunder dan sumber metabolit sekunder seperti terpenoid, steroid, kumarin, flavonoid dan alkaloid. Senyawa metabolit sekunder merupakan senyawa kimia yang umumnya mempunyai kemampuan bioaktivitas dan berfungsi sebagai pelindung tumbuhan tersebut dari gangguan hama penyakit untuk tumbuhan itu sendiri maupun lingkungan (Lathifah, 2008).

Kondisi geografis dan keadaan wilayah propinsi Bengkulu yang masih banyak hutan dimungkinkan banyak ditemukan berbagai jenis tumbuhan yang tergolong metabolit sekunder dan digunakan oleh masyarakat sebagai obat tradisional, Salah satu jenis tumbuhan yang digunakan sebagai obat oleh masyarakat adalah biji kebiul (Caesalpinia $s p$ ) (bahasa daerah Bengkulu).

\section{METODE PENELITIAN}

1. Penyedian Sampel Biji Buah Kebiul

2. Uji pendahuluan Bahan Alam Sekunder

3. Identifikasi Senyawa metabolit

4. Ekstraksi dan fraksinasi Senyawa Biji Kebiul

5. Uji aktivitas ekstrak biji kebiul (Caesalpinia sp)

6. Penyediaan mencit (M. musculus) Jantan
Mencit yang digunakan adalah yang berumur 6 - 8 minggu dengan berat badan 20 - 30 g sebanyak 25 ekor kemudian dibagi menjadi 5 kelompok, yaitu kelompok kontrol P0, kelompok perlakuan P1, P2, P3, $\mathrm{P} 4$, dan P5 masing-masing kelompok terdiri dari 5 ekor.

7. Konversi dosis

Dosis yang disesuaikan dengan penelitian sebelumnya. Dosis efektif $0,028 \mathrm{~g} / \mathrm{KgBb}$ dan $0,056 \mathrm{~g} / \mathrm{KgBb}$ (Fitrianingsih, 2010).

8. Pengembangan Plasmodium berghei

9. Pemeriksaan parasitemia

10.Pemberian perlakuan

11.Pengamatan eritrosit

Jumlah Sel-sel Darah Merah $(\mathrm{SDM})=\mathrm{Ne} x$ $\mathrm{p} \times 50$

Keterangan : Ne $=$ Jumlah Sel-sel Darah Merah dalam lima kotak.

$\mathrm{P}=$ Pengenceran100X (Gandasoebrata, 2007).

12.Isolasi dan Pemurnian pada fraksi etil asetat.

13. Semua fraksi hasil KLT dianalisis di bawah sinar UV $254 \mathrm{~nm}$ untuk menentukan jumlah noda dan rf tiap fraksi pada tiap eluens. Isolasi dilanjutkan dengan menggunakan Kromatografi Kolom (KK) dengan fase diam silaka gel $60 \mathrm{H}$ dan eluen yang memiliki $r \mathrm{f}$ terjauh hasil KLT.

14.Identifikasi dengan Spektrofotometri

Isolat yang diperoleh dari fraksi etil asetat diidentifikasi secara spektrofotometri menggunakan spektrofotometer IR, spektrofotometer UV-vis. dan spektrofotometer GC-MS. Indentifikasi tumbuhan dilakukan oleh tim ahli dari Laboratorium Biologi Lembaga Ilmu Pengetahun Indinesia (LIPI) di Cibinong.

\section{Analisis Data}

Data dianalisis dengan analisis varians (ANOVA)

\section{Prosedur Penelitian Pendidikan}

1. Studi pustaka tentang LKS

2. Pengembangan LKS

3. Validasi ahli

4. Revisi Produk

5. Uji coba terbatas

Uji coba terbatas akan dilaksanakan di kelas dengan desain one-group pretespostes. 


\section{Waktu dan Lokasi Penelitian}

Waktu penelitian dilakukan pada JanuariMei 2014 di Kebun Biologi FKIP UNIB.

\section{HASIL DAN PEMBAHASAN}

Biji Caesalpinia sp telah diuji dan hasilnya dapat dilihat pada Tabel 1. Semengtara itu senyawa aktif yang terkandung dari batang $J$. Multifida. L adalah senyawa golongan flavonoid yaitu flavonol glikosida yang dapat diisolasi dari fraksi etil asetat batang $J$. multifida L (Partikasari, 2012). Flavonol glikosida ini merupakan salah golongan dari flavonoid (Pietta, 2000) yang dapat digunakan sebagai antiplasmodium. Dalam senyawa flavonoid mengandung kuersetin yang berasal dari isolasi glikosida flavonoid yang memiliki aktivitas biologis sebagai antivirus dan antiparasit. Senyawa flavonol glikosida dapat menghambat pertumbuhan P.berghei dengan cara mematikan parasit (Fauziah, 2010).

Tabel 1. Hasil Uji Fitokimia Biji Caesalpinia sp

\begin{tabular}{llccc}
\hline \multirow{2}{*}{ Parameter Uji } & \multicolumn{3}{c}{ Ekstrak Sampel } \\
\cline { 2 - 5 } Alkaloid & Wagner & Etil Asetat & Etanol & N-Heksana \\
& Meyer & + & + & + \\
& Dragendorf & + & + & + \\
Flavonoid & & + & + & + \\
Saponin & + & + & + \\
Steroid & - & - & - \\
Terpenoid & + & + & - \\
Tanin & - & - & + \\
\hline
\end{tabular}

Rata-rata jumlah eritrosit yang tidak terinfeksi dapat dilihat pada Gambar 1. Secara umum mekanisme bagaimana obat antiplasmodium dapat mematikan plasmodium sehingga dapat menghambat pertumbuhan plasmodium sehingga dapat meningkatkan jumlah eritrosit adalah saat obat antiplasmodium masuk secara oral ke dalam lambung, obat akan masuk ke usus besar dan kemudian ke usus halus, di usus halus terjadi penyerapan (absorbsi) oleh sel epitel. Sebelum masuk ke pembuluh darah dan sel target (hati). Obat akan menuju ke organ jaringan terlebih dahulu (yaitu hati, otot, jantung, dan otak). Kemudian masuk ke sumsum tulang belakang sebagai aktivator sel darah merah, kemudian masuk ke jaringan hati, dan pembuluh darah (Simanjuntak, 2007).

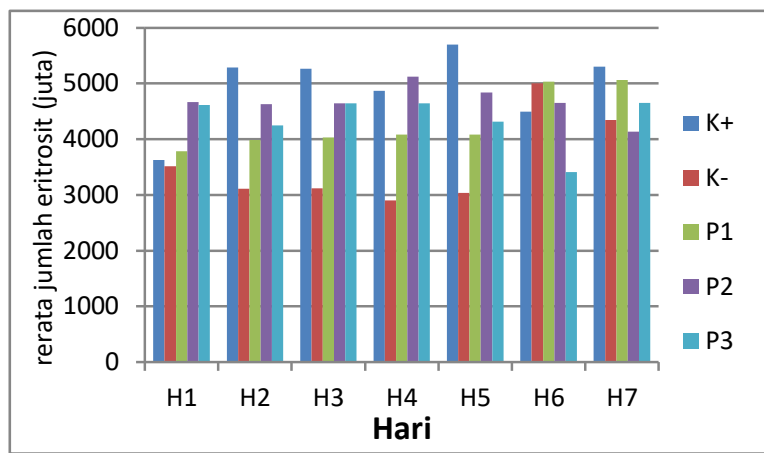

Keterangan:

$\mathrm{K}+($ kontrol +$)$ : Kloroquin

K- (kontrol -) : Minyak zaitun

P1 (dosis 1) : Ekstrak J. multifida L $0.028 \mathrm{~g} / \mathrm{kgbb}$

P2 (dosis 2) : Ekstrak J. multifida L $0.056 \mathrm{~g} / \mathrm{kgbb}$ )

P3 (dosis 3): Ekstrak J. multifida L $0.084 \mathrm{~g} / \mathrm{kgbb}$ )

Gambar 1. Grafik Rata-rata jumlah eritrosit tidak terinfeksi.

Haemoglobin di dalam sel darah merah menghasilkan asam amino yang menjadi nutrient bagi parasit dan juga menghasilkan zat toksit yang disebut ferryprotoporphyrin (FP IX). Sehingga obat aktif yang dimetabolisis menjadi metabolit yang bersifat toksik dengan zat toksit membentuk suatu senyawa kompleks yang meracuni vakuola sebagai nutrient atau sumber nutrisi bagi P.berghei sehingga akan kelaparan dan kemudian mati (Syamsudin, 2005).

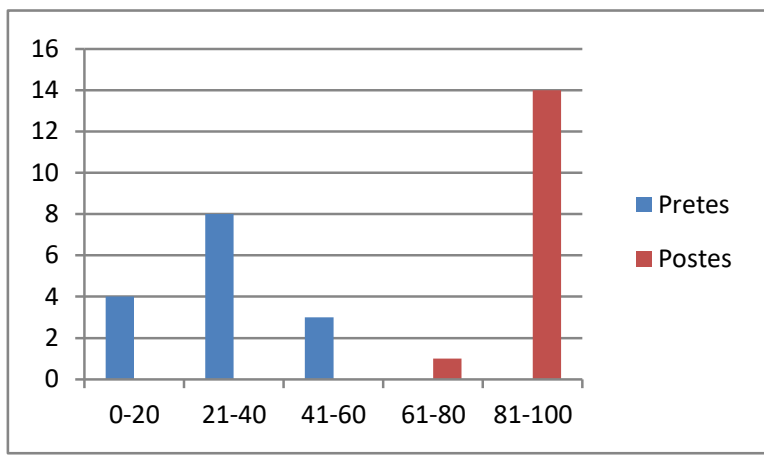

Gambar 2. Grafik hasil pretes dan postes

Hasil penelitian pendidikan menunjukkan adanya perbedaan hasil belajar kimia pada siswa MAN 1 Kota Bengkulu dengan pembelajaran yang menggunakan LKS melihat dari pretes dan postes, nilai rata-rata postes lebih besar dari pretes. Keberhasilan penggunaan LKS dan peningkatan hasil belajar ini karena beberapa hal, di antaranya siswa lebih aktif dalam proses belajar mengajar, menumbuhkan kepercayaan 
diri pada siswa dan meningkatkan motivasi belajar, serta rasa ingin tahu. (Trianto, 2009) Selain itu, memudahkan siswa untuk menyelesaikan tugas perorangan, kelompok atau klasikal karena siswa dapat menyelesaikan tugas sesuai dengan kecepatan belajarnya.

Hasil penelitian menunjukkan bahwa tidak semua siswa mendapatkan nilai di atas rata-rata kelas, hal ini dikarenakan siswa tersebut kurang berpartisipasi dalam melakukan eksperimen dan menyampaikan pendapat dengan anggota kelompok sehingga pemahaman siswa mengenai materi kurang. Selain itu, terdapat perbedaan kemampuan siswa dalam menguasai konsep yang diberikan (Suprijono, 2011).

\section{KESIMPULAN}

Ekstrak biji Caesalpinia sp mengandung senyawa aktif metabolit sekunder yaitu alkaloid, flavonoid, saponin, dan terpenoid. Pemberian ekstrak kasar biji Caesalpinia $s p$ berpengaruh terhadap penurunan jumlah P.berghei dalam darah mencit. Pada dosis $0.056 \mathrm{~g} / \mathrm{Kgbb}$ menunjukkan aktivitas penghambatan terbesar yakni $42.89 \%$ dibandingkan dengan dosis yang lainnya. Perbedaan hasil belajar siswa dengan menggunakan LKS setelah dievaluasi dengan pretes dan, hal ini terlihat dari rata-rata postes sebesar 88.6 lebih tinggi dari pada rata-rata pretes yaitu 32.1

\section{DAFTAR PUSTAKA}

Fauziah, L. 2010. Isolasi Glikosida Flavonoid Dari Daun Ketela Pohon. Pharmacy Community.

Fitrianingsih S.P, Supriatna, Diantini A, Muis A. 2010. Aktivitas Antiplasmodium ektrak etanol beberapa tanaman obat terhadap mencit yang terinfeksi Plasmodium berghei. Prosiding SNaPP 2010. Edisi Eksakta.

Gandasoebrata. 2007. Penuntun Laboratorium Klinik. Jakarta: Dian Rakyat.

Lathifah, Q. 2008. Uji efektifitas ekstrak kasar senyawa antibakteri pada buah belimbing wuluh (Averrhoa bilimbi L.) dengan variasi pelarut. Doctoral dissertation.
Malang: Universitas Islam Negeri Maulana Malik Ibrahim

Marwoko, M. T. B. 2013. Isolasi, Identifikasi dan Uji Aktifitas Senyawa Alkaloid Daun Binahong (Anredera cordifolia (Tenore) Steenis). Chem Info Journal, 1(1), 196201.

Partikasari, R. 2012. Uji aktivitas ekstrak batang J. multifida. L terhadap jumlah Eritrosit Mus musculus yang diinfeksi p. Berghei dan Aplikasinya dalam pembelajaran kimia dengan menggunaka Media audio visual. [Tesis]. Bengkulu: Universitas Bengkulu.

Pietta P.G. 2000. Flavonoids as antioxidants. Journal of Natural Products. Vol. 63, pp. 10350- 1042, 2000

Simanjuntak, M. T. 2007. Aspek Biofarmasi Mekanisme Absorpsi Obat: Peranan Monocarboxlic Acid Transporter-1 (MCT1) Terhadap Absorpsi Obat Dalam Usus Halus. Aspek Biofarmasi Mekanisme Absorpsi Obat: Peranan Monocarboxlic Acid Transporter-1 (MCT-1) Terhadap Absorpsi Obat Dalam Usus Halus..

Suprijono, A. 2009. Cooperative learning: teori \& aplikasi PAIKEM. Pustaka Pelajar.

Syamsudin. 2005. Mekanisme Kerja Obat Antimalaria. Jurnal Ilmu Indonesia. April 2005. Hal 37-40. Vol.3. No. 1.

Trianto. 2009. Inovatif- Mendesain Model Pembelajaran Progresif. Jakarta: Predana Media. 